\title{
Toward increased engagement between academic and indigenous community partners in ecological research
}

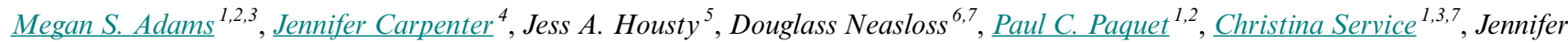 \\ Walkus $^{8}$ and Chris T. Darimont ${ }^{1,2,3}$
}

\begin{abstract}
Ecological research, especially work related to conservation and resource management, increasingly involves social dimensions. Concurrently, social systems, composed of human communities that have direct cultural connections to local ecology and place, may draw upon environmental research as a component of knowledge. Such research can corroborate local and traditional ecological knowledge and empower its application. Indigenous communities and their interactions with and management of resources in their traditional territories can provide a model of such social-ecological systems. As decision-making agency is shifted increasingly to indigenous governments in Canada, abundant opportunities exist for applied ecological research at the community level. Despite this opportunity, however, current approaches by scholars to community engaged ecological research often lack a coherent framework that fosters a respectful relationship between research teams and communities. Crafted with input from applied scholars and leaders within indigenous communities in coastal British Columbia, we present here reflections on our process of academic-community engagement in three indigenous territories in coastal British Columbia, Canada. Recognizing that contexts differ among communities, we emerge with a generalizable framework to guide future efforts. Such an approach can yield effective research outcomes and emergent, reciprocal benefits such as trust, respect, and capacity among all, which help to maintain enduring relationships. Facing the present challenge of community engagement head-on by collaborative approaches can lead to effective knowledge production toward conservation, resource management, and scholarship.
\end{abstract}

Key Words: aboriginal; collaborative research; community engagement; ecology; First Nations; indigenous communities; natural science; resource management; social-ecological systems; trust

\section{INTRODUCTION}

Ecological research increasingly focuses on applied and integrated approaches to resolve complex issues of conservation and management of natural resources. Many ecologists now recognize that local perspectives and the implications of their research should be considered. Despite this realization, ecological research often lacks a consideration of the potential costs and benefits of the research process and its outcomes on local residents. However, multidisciplinary approaches to ecological research that incorporate social dimensions provide increasingly effective approaches by which to consider the impacts of research for local people (Berkes 2004, Deur and Turner 2005, Drew 2005, Trosper 2009, Housty et al. 2014).

Such applied ecological research is often conducted alongside human communities within the broader, natural, ecological community. The people, organizations, and governments within and among these communities constitute social-ecological systems; they maintain direct experiences, dynamic relationships, and governance systems tied to local ecology through economic, social, and cultural connections (Berkes 2004, Brown and Brown 2009, Ostrom 2009). Such communities may be indigenous or nonindigenous. Indigenous communities, however, often serve as the center of local governance within large landscapes (e.g., villages, or "reserves" within traditional territories since the passage of the Indian Act of 1876 in Canada). We hereafter refer to these autonomous, indigenous nationhoods as Nations. The intimate and ancient relationships with the natural environment within the territories of Nations far precede the recent claims of colonial governments.
Residents of these communities hold dynamic local or traditional ecological knowledge. A combination of adaptively evolving practice, belief, and knowledge of natural systems, this knowledge is transmitted culturally through generations over millennia (Johnson and Ruttan 1993, Heiltsuk Tribal Council 2001, Berkes 2008). This multidimensional knowledge provides an understanding of local and interconnected patterns and processes over large spatial and temporal scales, such as insight into effects of harvesting, cycles of resource availability, and shifts in climate or ecosystem structure and function (Heiltsuk Tribal Council 2001, Haggan et al. 2006, Turner and Berkes 2006, Parrotta and Trosper 2012). Local ecological knowledge differs from traditional ecological knowledge in that it is not values-based, but instead, is built on years of empirical observations. As a result of this collective local and traditional knowledge among members, communities represent focal points for information that can help shape strategies for active conservation and land management (Pretty 2003, Gutiérrez et al. 2011).

Despite the experience within communities in employing local social-ecological management systems of their own making, the current paradigm of western science-influenced resource management and conservation planning dominates in Canada and beyond. This practice relies on the scientific process to generate information to inform management policies that are applied over large geographical and temporal scales. Plans are typically implemented through centralized bureaucracies such as provincial or federal governments (Dietz et al. 2003, Armitage 2005). Conservation and resource management strategies often comprise the end results, which can protect or restore key areas

${ }^{1}$ Department of Geography, University of Victoria, ${ }^{2}$ Raincoast Conservation Foundation, ${ }^{3}$ Hakai Beach Institute, ${ }^{4}$ Heiltsuk Integrated Resource Management Department, ${ }^{5}$ Qqs Projects Society, ${ }^{6}$ Kitasoo/Xai-Xais Integrated Resource Authority, ${ }^{7}$ Spirit Bear Research Foundation, ${ }^{8}$ Wuikinuxv Nation Fisheries 
and species from further exploitation or otherwise harmful human activities.

Notwithstanding potential ecosystem benefits, this centralized, science-based model faces increased scrutiny when communities and local governments do not share common land-use goals with outside institutions, or when they are not considered equal stakeholders in the planning process. Broadly, and across sectors from fisheries to land management, communities have shown dissatisfaction with the external influence of centralized, colonial bureaucracies in the process and outcomes of resource management (Armitage 2005, Loring 2013). For example, despite the fishing industry of Alaska, USA, being touted as a model of sustainable scientific management, many people and fishing communities consider themselves marginalized or disenfranchised in their ability to participate in government-managed fisheries (Loring 2013). Moreover, in any system, western scientists may conceive questions and conduct research without considering how traditional or local ecological knowledge could inform their research, or how the application of research outcomes could compromise local conservation and management strategies (Schnarch 2004, Gearheard and Shirley 2007). To address these conflicts, academic practitioners can collaborate with local communities toward common objectives for the conservation of both natural and local human systems.

Such a partnered approach appears to occur more commonly now, at least in theory. Ecologists and policy-makers increasingly recognize that community-based approaches and/or comanagement can achieve relevant, sustainable outcomes in resource management (Ban et al. 2008, Ostrom 2009, Gutiérrez et al. 2011, Leys and Vanclay 2011). This realization was derived in part because of the scale of community governance over socialecological systems. Community governance is localized or heterogeneous, quintessentially de-centralized, and is effective compared to or when coupled with larger scales of governance (Johannes 2002, Dietz et al. 2003, Armitage 2005). For example, recent empirical tests show that the behaviors that best predict successful (i.e., sustainable) fisheries are almost exclusively expressed at the local level (Gutiérrez et al. 2011). Such evidence, and the strong theory on which it rests, presents academic ecologists with an opportunity to engage with communities. Correspondingly, research supported by academics may provide community leadership with information that can be valuable for governance and conservation of local resources (e.g., Ban et al. 2008).

Community engaged research provides a method by which these opportunities can be realized. It occurs when members of communities and research-based institutions collaborate throughout the research process toward shared outcomes. For example, Huntington et al. (2011) recognize the immense value of collaborative fieldwork and input from local experts in their investigations of ecological factors and harvesting techniques in population dynamics of black leather chitons (Katharina tunicata) in south-central Alaska. Alternatively, indigenous governments now commonly employ academics to summarize ecological information or analyze existing data for their benefit (i.e., Offshore Oil and Gas Research Group 2004), either to inform management decisions or to understand effects of resource extraction and development on local social-ecological systems.
Regardless of direction, community engaged research requires that each party seeks to enhance individual strengths and cultivate benefits from research by respecting and working together throughout the process. Despite this potential, current approaches to academic ecological research may not recognize opportunities for collaborative engagement (Huntington et al. 2011). For example, in our experience, visiting scholars might not involve communities in the conception of ecological research, respect cultural protocols when operating on the landscape, or communicate information and research outcomes in a manner that is understandable

To enable engagement in future research endeavors, ecologists can seek guidance from others. For example, both individual leaders within communities and local protocols (e.g., Heiltsuk Tribal Council 2001) can provide direction. Other academic disciplines that have training and exposure to contemporary social science practice and that work toward an ethic of community engagement can also be important. For example, the fields of geography, anthropology, and health have developed ethical guidelines for engagement in their research processes (Cochran et al. 2008, Bull 2010, Castleden et al. 2012).

Here, as members of a collaborative research team consisting of academic ecologists and community experts, we present a working model for engagement between academics and indigenous communities. The model is based on our past and present experiences. We start by identifying the contemporary political context in which communities and ecologists are situated in Canada and beyond. We then identify current limitations toward community engagement. Finally, we provide a framework of key principles and roles within the research process that can yield new knowledge and a mutually beneficial process by which research can occur. Although we focus on the ecological experience, we recognize that the principles, process, and limitations of community engagement could be applicable across disciplines, especially within the natural sciences.

\section{THE CASE FOR COMMUNITY ENGAGED RESEARCH}

Contemporary and rapid changes to governance structures in Canada, and elsewhere, create a need for community engaged research. Abundant evidence suggests that centralized bureaucracies have not governed natural resources effectively, in part because they disregard the complexities of social-ecological systems (Holling and Meffe 1996, Folke et al. 2002). This can be reflected in the collapse of global fisheries and mismanagement of forest and water resources (Ostrom 2009). However, the capacity of large, centralized bureaucracies to manage resources is waning (e.g., Hoag 2012, Reynolds et al. 2012). Environmental legislation might also face erosion if it presents an impediment to industry or development (Lemos and Agrawal 2006, Todorovich and Schned 2012). As a consequence, environmental legislation might be enforced ineffectually and address inadequately the inherent complexities in the management of natural resources. These conditions are now prominent in Canada (e.g., recent dismantling of the Fisheries Act; Favaro et al. 2012, de Kerckhove et al. 2013).

This gap in effective governance created by retreating or neutered centralized government agencies provides opportunities for the resurgence of indigenous communities and their own governments. Co-management, formalized acknowledgement, 
and state legitimization of indigenous governance systems, such as land claims arrangements in Canada, Australia, New Zealand, and elsewhere, are being bolstered by rapidly changing legal landscapes (Houde 2007, Berkes 2009, Weiss et al. 2013). For example, Canada's Constitution Act of 1982 recognizes that indigenous people hold rights to areas and resources within their recognized territories. Moreover, government processes that propose resource extraction must consult and accommodate indigenous governments (Government of Canada 1982). To acknowledge these rights and avoid legal conflicts, recent policy agreements have shifted regional decision-making agency toward indigenous governments in both co-management and government-to-government processes (e.g., Wyatt 2008, Berkes 2009, Housty et al. 2014).

This transition can be illustrated with the Reconciliation Protocol in British Columbia, Canada, where we live and work. This agreement was negotiated between a group of Nations collectively referred to as "Coastal First Nations" and the Province to address the duality of title and a process for joint decision-making in governance over land and resource use (Coastal First Nations and Government of British Columbia 2011). The Protocol recognizes Coastal First Nations authority and provides a collaborative government-to-government platform to implement land- and marine-use planning, apply ecosystem-based management, and oversee economic development in the coastal region, popularly referred to as the Great Bear Rainforest (McGee et al. 2010, Coastal First Nations and Government of British Columbia 2011).

Despite recent policy developments that recognize regional authority such as this, however, indigenous governance and regional capacity to manage resources has yet to be implemented broadly. Although decision-making agency is being shifted to indigenous governments, we note that authority cannot be endowed to Nations whose authority is considered inherent. In addition, western-based governance systems within which indigenous governments must operate, such as laws and negotiation processes, are neither of indigenous design nor contribution, and are often the products of ineffective or failed management approaches of the past. Implementing such processes and reconciling these governance paradigms requires enormous financial and skill-based capacity, sustained support as this capacity builds, and information about resources and land use. Consequently, the capacity to conduct resource managementrelated research at a territorial scale is still developing for many indigenous communities (Tobias 2000), including those considered here: Bella Bella, Klemtu, and Wuikinuxv village. In theory, scholars of ecology or applied biology from academic institutions are well situated to provide a level of methodological and logistical capacity that can complement the contributions of local and traditional ecological knowledge. As we explain next, however, such partnerships require careful consideration of current limitations.

\section{LIMITATIONS OF CURRENT APPROACHES TO ENGAGED RESEARCH}

Although not universally the case, and recognizing that many individuals span perspectives, several deep cultural differences that stem from different values and beliefs, approaches, and reward systems exist in how academic and indigenous experts conduct what is labeled "research". Articulating these impediments humbly and openly can cultivate understanding and compassion between collaborators, which is a critical preliminary step in the engagement process.

Differences in the definitions of ecosystems present one major barrier. Scholars, policy-makers, and conservation planners have often framed ecosystems by the western notion that they are pristine, largely unaltered, and independent of interaction with local peoples (Pretty 2003, Deur and Turner 2005, Dent 2013). This conception differs strongly from the values and land-use practices of place-based communities, which are necessarily integrated with local ecology (Berkes 2008). A consequence of this divergence (and the recent hegemony of the western-based worldview) has been the establishment of protected areas that limit or exclude humans from land they have long inhabited (Pretty 2003, Dowie 2009).

Another problem is a culture of distrust of western science, which stems from mismanagement of local resources by science-based institutions. Moreover, prescriptive, quantitative management objectives that allocate resources for maximum economic yield have often seldom benefited indigenous communities or the condition of resources on which they depend (Pinkerton 1999, Walter et al. 2000, Pinkerton and Silver 2011). For example, marine resources managed through maximizing harvest quotas for non-local license holders have been substantially depressed in many regions of the Pacific Northwest (Pinkerton 1999).

Scholars and community members also often have divergent approaches toward research. The differences are often driven by their respective knowledge systems. Academic ecological research questions are founded on established theory and relevant literature and pursued by empirical or experimental methods (Weiss et al. 2013). In contrast, indigenous approaches are contextualized by local and traditional knowledge of biodiversity and sustainable resource management as part of complex socialecological systems (Brown and Brown 2009). Although ample attention has been given to these differences (Ingold and Kurttila 2000, Cruikshank 2001, Houde 2007), few studies explore establishing productive relationships that bridge these different knowledge systems and/or knowledge holders (but see ParradoRosselli 2007, Huntington et al. 2011, Housty et al. 2014). Moreover, indigenous communities have often not been included in the research process adequately. Instead, communities have often been regarded only as a source of local knowledge for the sake of extraction and integration into research design or resource management. Ultimately, such research outcomes serve the state or researchers rather than local or traditional knowledge holders (Nadasdy 2003, Davidson-Hunt and O'Flaherty 2007, Castleden et al. 2010, Bohensky and Maru 2011).

Compounding these problems is that local or traditional knowledge, or the needs of local communities, are often not factored into how and why research is conducted. While some researchers are highly accountable, our observation is that communities may not experience beneficial outcomes (such as compensation or communication of research findings) from participation in the research process. Instead, western notions of information or evidence and approaches to its collection have been thrust upon indigenous Nations. 
Capacity barriers, especially those related to funding and timing, might also limit interactions. Community resource managers and academics receive funding to produce deliverables such as policies or publications; upfront funding required for the time to develop the research process jointly (at either universities or in communities) and to cultivate the necessary trust might not be available. This may be compounded by the reality that junior scholars and/or smaller communities generally receive less funding overall. Although policy-based and financial endorsement for community engagement from academic institutions is increasingly evident, recipients may find it difficult to reconcile their community commitments with the typical academic reward structure (Nicotera et al. 2012). Moreover, whereas research publications often take years to compile, communities may wish results to be communicated more rapidly and directly; the capacity of both parties to translate and interpret information in a timely manner and via suitable means might often be lacking. Finally, indigenous communities might want to build trustworthy collaborations and be deliberate in the direction of research, which necessarily takes time and may conflict with schedules of academic researchers.

These barriers often relate to different reward systems. Whereas a passion for science and conservation might have originally attracted scholars to their vocation, academic research is in large part motivated by research interests, followed by awarding of degrees, the pursuit of publication, and receipt of grants. In contrast, indigenous resource managers and practitioners often pursue research for the stewardship of single resources and the social and ecological systems within which they are embedded (Haggan et al. 2006, Tobias 2010). Such stewardship is built upon complex connections to ecology, with a view to sustaining such connections for future generations (Brown and Brown 2009).

Finally, these limitations in the traditional model of academic research are further, and ultimately, compounded by a broader lack of trust between indigenous and nonindigenous peoples. This stems from a history of imposed assimilation techniques following European contact (e.g., residential schools in Canada). Violence, oppression, and discrimination toward indigenous peoples in the past and present may have potent implications for collaborations (Smith 1999). Many people (or their families) who have endured these abuses are the same community members with whom scholars of colonial ethnicities interact, which can influence day-to-day interactions and the establishment of trust.

Collectively, these limitations conspire so that the design and implementation of ecological research led by either party may not solicit input or participation from other knowledge systems. Outsiders (researchers) have often driven academic research, identifying the scope, methodologies, protocols, pace, and meeting of objectives, thus ultimately controlling how information is generated and shared (Davidson-Hunt and O'Flaherty 2007). In addition, without community participation in the forming of the research questions or the methodologies that follow, any inclusion of local and traditional ecological knowledge is often left unexplored or misunderstood and may not fully benefit academic efforts. Academic and community partners can begin to reconcile these limitations by acknowledging cultural differences and working reciprocally toward relevant research goals (Davidson-Hunt and O'Flaherty
2007). The engaged approach to the research process that we propose can provide a means toward realizing shared goals and productive research outcomes.

\section{PROPOSED FRAMEWORK FOR COMMUNITY ENGAGED APPROACHES TO ECOLOGICAL RESEARCH}

Confronting these problems and scoping new opportunities, we present our reflections on developing open and communicative approaches to the engagement process. We consider it a work in progress for all ecologists and communities in which community members have tangible input to the research process and in which outcomes are jointly determined. Because of the inherent complexity and cross-cultural challenges of such a process, we conceptualize engagement in a framework from both perspectives in three components. We first identify core principles that drive an engaged research process. Second, we outline the suite of possible roles for partners at each research stage. Third, we address the "process benefits," or tangible, reciprocal benefits of the research process itself, above and beyond the end results of newly generated knowledge. Although not in any sense faultless, prescriptive, or a finished product, in our experience, this approach can yield productive and enduring relationships between academics and community members for locally driven research.

Our aim is broad applicability. We first note that academics can be part of communities, just as community members can be researchers. While we recognize significant crossover, for our current purposes, we have framed the research process through the binary roles of academic and community collaborators. Second, we also note that while this framework has developed through long-standing relationships between indigenous leaders and applied scholars in coastal British Columbia, its generalizable nature could have broad relevance for any other communities and scholars seeking an ethic and practice of engagement.

\section{Foundational principles}

At its core, an engaged research process can be built upon a consideration of how research questions are framed, the consequences of research outcomes at local scales, and respect for place. Essential to these principles is acknowledging that indigenous forms of inquiry and monitoring are most often located in a cultural context different from that of western science and its methods. This necessarily involves an awareness of cultural differences and respectful interpersonal relationships (DavidsonHunt and O'Flaherty 2007, Gearheard and Shirley 2007, Parrado-Rosselli 2007).

Several local dimensions can provide context for a research question. First, given the rapid legal changes noted above, communities might initially wish to frame their research questions according to their legally-entitled management needs. Second, local and traditional ecological knowledge can inform how research questions are shaped. In this way, the collaborative perspectives of academics and communities can yield productive research questions that reflect local and complex social-ecological circumstances (Heiltsuk Tribal Council 2001, Housty et al. 2014). Third, we recognize that there will be variation in how questions are framed. For example, communities differ from one another and throughout time. Consideration should therefore be given to 
whose voices are being heard, and who is excluded, in framing research questions (Tobias 2010). Clarifying and challenging the assumptions behind the conception of research is critical for all of these dimensions.

The social-ecological needs of the community in the short and long term can direct the research process (Heiltsuk Tribal Council 2001, Gearheard and Shirley 2007, Huntington et al. 2011). Academics have a responsibility to understand how their shortterm research efforts can fall into the broader framework of the community's vision. This can inform the distribution of present and future benefits and costs of the research outcomes for the community, as well as the structure of the research (Tobias 2000). Reconciling the research process to generate information across desired time scales for urgent local management decisions or longer-term monitoring is important for community collaborators. It is also important to consider the implications of research to the political balance among neighboring communities and/or Nations. Where research takes place in a territory with overlapping claims, working with one Nation (and not with others) can have far-reaching and unintended effects in resource management and potential land claims processes that should be carefully considered and discussed.

Finally, respecting the place-based setting and authority of the community is integral to an engaged research approach. By this we mean respect for the landscapes and resources as integral aspects of a community's experience and knowledge systems; not simply a "study site" or a place to conduct "fieldwork" for scholars, but instead, as part of a complex system to which human communities also belong (Heiltsuk Tribal Council 2001, Castleden et al. 2010). This respect can be demonstrated simply through word choice (i.e., academic partners refraining from possessive pronouns and concepts embodied in, for example, "my study area"). More broadly and deeply, respect can be modeled by engaging with the wider community and giving back to that specific place. For example, researchers could engage with youth and/or cultural events, respecting protocols in the community and on the land, or by visiting community collaborators and friends outside of the field season. These actions signal a longer commitment to, and relationship with, the people and landscapes where research occurs.

\section{Stage-by-stage framework of the research process}

To complement these core principles, we provide a framework for engagement at each stage of the research process. While we recognize that engagement does not always follow a simple linear chronology, our model addresses the collaborative experience at each stage (Table 1). We identify the contributions that academics and indigenous community members can provide, as well as suggest the process benefits that can emerge at each stage. The latter include: respect, trust, co-capacity building, and enduring relationships. Generally, our experience shows us that these outcomes commonly occur in that order (Fig. 1). We have developed this framework based on our shared experiences and goals for an engaged research process, supplemented with insight from the literature (e.g., Turner and Carpenter 1999, Schnarch 2004, Drew 2005, Davidson-Hunt and O'Flaherty 2007, Gearheard and Shirley 2007, Bull 2010, Huntington et al. 2011, Tobias et al. 2013). Although we aim for generalizability, we recognize that this framework might particularly benefit larger projects, which are generally resourced better and operate on time frames over which respect and trust can be more effectively cultivated and maintained. This does not imply, however, that smaller projects cannot incorporate engagement as they occur.

Fig. 1. Research outcomes (green) and reciprocal process benefits (italicized font) generated through an engaged research process. Through each stage of research, community and academic partners can cultivate benefits, including respect, trust, co-capacity building, as well as open and enduring relationships. These benefits may feed back to previous stages. This allows for a dynamic research process and provides a foundation on which successive stages are built.

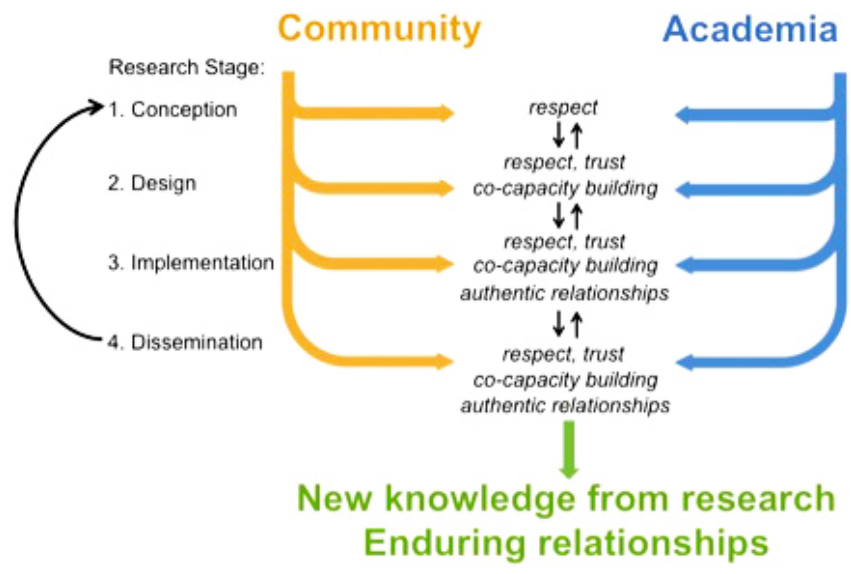

Beyond the direct research process, we believe it is important for the research team to engage with local residents at community events through all stages of the research process. Examples of this include spending time with youth or school groups, feasting together, or the witnessing of cultural events. Likewise, scholars can welcome community collaborators to university environments, conferences, or on supervisory committees. It is important to build time for experiences such as these into an otherwise typical "field season" for academics that usually involves considerable pressure to complete and publish projects in a timely manner (Schnarch 2004).

\section{Stage 1: conception of research focus and questions}

The research process begins with identifying desired outcomes in the application of research. These are often derived through local requirements and informed by local and/or traditional knowledge, typically with applications for resource management or conservation. Both academic and community stakeholders need to identify and examine their assumptions prior to identifying specific research questions. By considering the potential knowledge systems and variables that provide the context of the research focus, collaborators can establish clear and productive research questions.

Communities may identify potentially suitable researchers and engage or hire them toward a research goal. Alternatively, researchers might approach communities, but would do so by considering their potential needs. In addition, academic partners might articulate additional research questions of theirs for 
Table 1. Roles and contributions by community and academic collaborators at the conception, design, implementation, and dissemination stages of community engaged research. This is a nonexclusive suite of possible roles; in practice, collaborations might take different forms. We recognize that community members might also be academics, but for simplicity, we identify binary roles.

\begin{tabular}{|c|c|c|c|}
\hline \multirow[b]{2}{*}{ Research stage } & \multirow[b]{2}{*}{ Research step } & \multicolumn{2}{|c|}{ Role or contribution } \\
\hline & & Community partners & Academic partners \\
\hline \multirow[t]{3}{*}{ Conception } & Identify research focus & $\begin{array}{l}\text { Formulate research questions } \\
\text { within local context of TEK/ } \\
\text { LEK } \dagger \text { and research goals }\end{array}$ & $\begin{array}{l}\text { Situate local context into } \\
\text { scholarly framework to shape } \\
\text { research focus }\end{array}$ \\
\hline & Examine assumptions & & \\
\hline & $\begin{array}{l}\text { Establish research questions } \\
\text { beneficial to all parties }\end{array}$ & & \\
\hline \multirow[t]{3}{*}{ Design } & $\begin{array}{l}\text { Select appropriate scope and } \\
\text { methods }\end{array}$ & $\begin{array}{l}\text { Ensure methodology respects } \\
\text { local protocols }\end{array}$ & $\begin{array}{l}\text { Provide design expertise in } \\
\text { scientific methods }\end{array}$ \\
\hline & Organize local logistics & $\begin{array}{l}\text { Provide clear expectations on } \\
\text { research goals and data-sharing } \\
\text { agreements }\end{array}$ & $\begin{array}{l}\text { Contribute to shared vision for } \\
\text { project goals and data-sharing } \\
\text { agreements }\end{array}$ \\
\hline & Craft data-sharing agreements & $\begin{array}{l}\text { Suggest if current project can } \\
\text { build from/contribute to other } \\
\text { local research }\end{array}$ & \\
\hline \multirow[t]{4}{*}{ Implementation } & Assemble research team & $\begin{array}{l}\text { Ensure logistically safe and } \\
\text { culturally respectful research } \\
\text { operations }\end{array}$ & Share technical expertise \\
\hline & $\begin{array}{l}\text { Engage in collaborative } \\
\text { fieldwork }\end{array}$ & $\begin{array}{l}\text { Contribute local experts on } \\
\text { research teams }\end{array}$ & Respect local protocols \\
\hline & $\begin{array}{l}\text { Consult frequently on progress } \\
\text { and challenges }\end{array}$ & Share local knowledge & $\begin{array}{l}\text { Consult with community } \\
\text { regarding project progress }\end{array}$ \\
\hline & & Provide feedback on process & Provide feedback on process \\
\hline \multirow[t]{4}{*}{ Knowledge dissemination } & $\begin{array}{l}\text { Respect both access to and } \\
\text { confidentiality of knowledge }\end{array}$ & Respect data-sharing protocols & Respect data-sharing protocols \\
\hline & $\begin{array}{l}\text { Communicate research } \\
\text { outcomes }\end{array}$ & $\begin{array}{l}\text { Make knowledge accessible to } \\
\text { community }\end{array}$ & $\begin{array}{l}\text { Make knowledge accessible for } \\
\text { community }\end{array}$ \\
\hline & & $\begin{array}{l}\text { Potentially use information for } \\
\text { resource management decisions }\end{array}$ & $\begin{array}{l}\text { Potentially craft academic } \\
\text { publications }\end{array}$ \\
\hline & & $\begin{array}{l}\text { Participate in scholarly } \\
\text { publications, if appropriate }\end{array}$ & $\begin{array}{l}\text { Offer information for resource } \\
\text { management, if appropriate }\end{array}$ \\
\hline
\end{tabular}

$†$ Traditional or local ecological knowledge.

communities to consider, even if the questions are of no immediate or direct relevance to local people. Finally, communities with research needs may also opt not to involve academic capacity, but instead, conduct their own research. In our view, the most mutually beneficial and productive collaborations could satisfy the resource management needs of the communities and their governments while simultaneously providing scholarly opportunity for academics (e.g., Housty et al. 2014). Identifying and negotiating these regions of overlap might require time and thoughtful consideration. Once potential collaborations have been identified, jointly prepared funding could be sought to increase the research and engagement capacity of both parties.

When conceptualizing specific research objectives, respect for each other's context and process can be demonstrated by considering the various approaches and needs of each party. Academic assumptions about a proposed system might differ from traditional or local ecological knowledge. For example, ecologists might see an ecological pattern or process as novel, or understand it through the framework of other ecological research (e.g., a migration pattern shift or switching of prey types by consumer species), whereas traditional or local knowledge might be able to place this observation within a larger perspective, where values are intertwined with site-specific knowledge (e.g., longterm weather processes, large temporal-scale population dynamics, and oral histories of human or animal land use; Berkes 2008). In this way, both academic and local and traditional knowledge provide a broad scale and a strong foundation that can address assumptions inherent to shorter-term research questions. Most importantly, it is crucial to consider the implications of research to communities, whether they be harmful or beneficial (Tobias 2000, Schnarch 2004). For example, if research prompts the conservation or use of an ecological resource, it is important to question how the access and cultural connection to, or governance of, that resource may be altered (and for whom). Openly and thoughtfully entered and navigated, this 
early stage of the research process can begin to build mutually informed respect and acceptance, which can cultivate trust between collaborators.

\section{Stage 2: research design}

Once the focus of a research project has been conceived, a research methodology and project plan can be developed that captures and accepts the shared vision of collaborators. Academics can provide expertise in creating approaches to data collection. Importantly, however, these should be consistent with local protocols and guiding principles for operating within the community, on the landscape, and with neighboring communities (e.g., Heiltsuk Tribal Council 2001, Schnarch 2004). This could be done by soliciting direct input from research collaborators or through processes that involve the broader community, such as workshops or information sessions. Inclusive project budgets can cultivate research support and capacity building for collaborators (Heiltsuk Tribal Council 2001). Communities can also suggest how other concurrent projects could support or contribute to proposed research. Negotiating data sharing, communication, and storage protocols at the onset of the project is essential to ensuring clear expectations about the ownership, control, access, and possession of information for collaborators (Schnarch 2004, Tobias et al. 2013). Collectively, these steps build and maintain acceptance and respect for both guiding principles and research approaches between collaborators through the learning and observation of scientific and cultural protocols. As capacity is shared and built into the design of research, so too is trust in the engagement process.

\section{Stage 3: implementation}

The research design can be implemented by a collaborative team of scholars, community experts, and other participants. On beginning a project, the team can consider how to engage and employ community members in research opportunities. Hiring local people for fieldwork can increase logistical safety and ease, while also helping to ensure local protocols are respected. When appropriate, local technicians can also share local ecological knowledge and cultural information about the landscape. Similarly, Nations might hire scientists and technicians for methodological and analytical capabilities. These capacities can be taught and shared between the research team and the community (Drew 2005). We also recognize that some individuals will bridge both worlds with backgrounds as academically trained practitioners or scholars and members of indigenous communities (e.g., White 2006, Moody 2008, Housty et al. 2014).

During implementation, partners develop one another's capacity while also building sincerely collaborative personal and professional relationships. By sincere, we mean respectful, lacking in condescension and/or ulterior motives in forming the relationship. As one example, collaborative fieldwork allows the research team to discuss and envision the ecological questions in situ (e.g., Huntington et al. 2011). Sharing observations as a team and with the broader community can have additional benefits such as the conception of alternative hypotheses or improved research methodologies. The mutual trust and respect further cultivated during co-capacity building can allow for a dynamic process that ensures the team is working toward the desired outcomes of all collaborators and that the research team and community can feel a sense of ownership and participation in the research.
Stage 4: use and dissemination of knowledge

Research ultimately generates information that can have scholarly value and community-based applications. Data-sharing protocols will permit appropriate accessibility and dissemination of information while also respecting ownership or confidentiality (Schnarch 2004, Castleden et al. 2010). When information is being synthesized to share with community members (likely in forms and forums different from those intended for scholarly products), it should be crafted to be accessible and informative, as well as conscious of potentially sensitive or confidential material. Communities might apply the information generated toward local governance strategies or an increased understanding of local social-ecological systems (Tobias 2010), whereas scholars might apply the information to test, improve, or create theory via the peer-reviewed publication process. Ideally, one reinforces and supports the other in ways that honor an engaged, collaborative process and the complexities of social-ecological systems.

When preparing scholarly publications, academics might include community members on the review or authorship process. If interest and contributions are consistent with typical publishing expectations, such inclusion is in fact expected (Castleden et al. 2010). At minimum, publications can be reviewed by and respectfully acknowledge the contributions of community collaborators. A collaborative review process involves careful consideration of the ethics of authorship through direct acknowledgement of the intellectual property of knowledge holders, crediting of community permissions and contributions, and respect for copyright and confidentiality agreements as negotiated at the onset of the research process or as per community protocols (Canadian Institutes of Health Research 2007). For example, academic and community co-authors may acknowledge or include other community members as co-authors given their significant contributions, despite this not being a conventionally academic approach to authorship (i.e., Castleden et al. 2010).

The partnerships built through these stages can lead to enduring relationships and even future collaborations (Fig. 1). In particular, respect for knowledge systems (acknowledgement of the validity of contributions), data protocols (clear boundaries of possession, ownership, and confidentiality), and implications of generated knowledge (understanding of where benefits and detriments of the research flow) provides a strong foundation for building enduring research partnerships (Turner et al. 2000, Schnarch 2004).

\section{CONCLUSIONS}

The interconnections of ecology, socioeconomy, culture, and politics in which research is embedded will remain uncertain and difficult to manage if actors and relationships are kept separate with their differences left unspoken. In other words, we believe a central guiding principle of this process is to be open and honest. Integrative approaches that incorporate local and traditional ecological knowledge and focus on the entire human-ecological system can generate productive questions, answers, and solutions to confront social-ecological challenges and opportunities.

As conventional scientists become more aware of indigenous knowledge and interactions within traditional territories, the gap between scientific inquiry and indigenous knowledge systems is narrowing and being bridged. In our case, this emerged out of an ecological and social-ecological context, but many of these 
principles could be useful to disciplines outside our domain in areas such geology, physical geography, and environmental science, as well as to those disciplines of applied, engaged, and critical social science. Ecological research and monitoring that involves indigenous communities as collaborators and/or drivers is inherently social and will involve various cultural and social perspectives. When a knowledge system and worldview does not separate people from place, western science cannot disregard the cultural influence that permeates the ecosystems in which research occurs. In our experience, community engagement, practiced with a sense of humility, respect for place and people, as well as an awareness of the complexities of the issues at hand, could present resolutions for current social-ecological challenges of conservation and resource management for indigenous communities and beyond.

This journey of learning will involve the academic community divesting its internalized processes and beginning to frame the process from the community context. It will also require direction from communities regarding if and how they wish to be involved or what capacity they require and can offer. This may come as a challenge for academics and communities, but we hope this challenge is balanced by sincere, productive, and enduring relationships generated through an increasingly engaged approach.

Responses to this article can be read online at: http://www.ecologyandsociety.org/issues/responses. $\mathrm{php} / 6569$

\section{Acknowledgments:}

We acknowledge and thank colleagues, mentors, and friends from the Heiltsuk, Kitasoo/Xai'Xais, and Wuikinuxv Nations as well as the University of Victoria for sharing their knowledge, friendship, and ideas with us, and for helping to foster authentic connections with place and people. We also acknowledge Dr. Jonaki Bhattacharyya for her support and insight throughout this process. The support of the Hakai Beach Institute, Natural Sciences and Engineering Research Council of Canada, Raincoast Conservation Foundation, Tula Foundation, and Spirit Bear Research Foundation has been integral to this work.

\section{LITERATURE CITED}

Armitage, D. 2005. Adaptive capacity and community-based natural resource management. Environmental Management 35 (6):703-715. http://dx.doi.org/10.1007/s00267-004-0076-Z

Ban, N. C., C. Picard, and A. C. J. Vincent. 2008. Moving toward spatial solutions in marine conservation with indigenous communities. Ecology and Society 13(1): 32. [online] URL: http:// www.ecologyandsociety.org/vol13/iss1/art32/.

Berkes, F. 2004. Rethinking community-based conservation. Conservation Biology 18(3):621-630. http://dx.doi.org/10.1111/ j.1523-1739.2004.00077.x

Berkes, F. 2008. Sacred ecology. Second edition. Routledge, New York, New York, USA.
Berkes, F. 2009. Evolution of co-management: role of knowledge generation, bridging organizations and social learning. Journal of Environmental Management 90(5):1692-1702. http://dx.doi. org/10.1016/j.jenvman.2008.12.001

Bohensky, E. L., and Y. Maru. 2011. Indigenous knowledge, science, and resilience: What have we learned from a decade of international literature on "integration"? Ecology and Society 16 (4): 6. http://dx.doi.org/10.5751/ES-04342-160406

Brown, F., and Y. K. Brown, editors. 2009. Staying the course, staying alive. Coastal First Nations fundamental truths: biodiversity, stewardship and sustainability. Biodiversity BC, Victoria, Canada. [online] URL: http://www.biodiversitybc.org/ assets/Default/BBC_Staying the Course_Web.pdf.

Bull, J. R. 2010. Research with Aboriginal peoples: authentic relationships as a precursor to ethical research. Journal of Empirical Research on Human Research Ethics: an International Journal 5(4):13-22. http://dx.doi.org/10.1525/jer.2010.5.4.13

Canadian Institutes of Health Research. 2007. CIHR guidelines for health research involving Aboriginal people. Canadian Institutes of Health Research, Ottawa, Canada. [online] URL: http://www.cahr.uvic.ca/nearbc/documents/2009/aboriginal/CIHRIAPH $\% 20$ Guidelines $\% 20$ for $\% 20$ Health $\% 20$ Research $\% 20$ Involving $\%$ 20Aboriginal $\% 20$ People.pdf.

Castleden, H., V. S. Morgan, and C. Lamb. 2012. "I spent the first year drinking tea": exploring Canadian university researchers' perspectives on community-based participatory research involving Indigenous peoples. Canadian Geographer 56 (2):160-179. http://dx.doi.org/10.1111/j.1541-0064.2012.00432.x

Castleden, H., V. S. Morgan, and A. Neimanis. 2010. Researchers' perspectives on collective/community co-authorship in communitybased participatory indigenous research. Journal of Empirical Research on Human Research Ethics: an International Journal 5 (4):23-32. http://dx.doi.org/10.1525/jer.2010.5.4.23

Coastal First Nations and Government of British Columbia. 2011. Reconciliation protocol, ammending agreement. Government of British Columbia, Victoria, Canada.

Cochran, P. A. L., C. A. Marshall, C. Garcia-Downing, E. Kendall, D. Cook, L. McCubbin, and R. M. S. Gover. 2008. Indigenous ways of knowing: implications for participatory research and community. American Journal of Public Health 98 (1):22-27. http://dx.doi.org/10.2105/AJPH.2006.093641

Cruikshank, J. 2001. Glaciers and climate change: perspectives from oral tradition. Arctic 54(4):377-393. http://dx.doi. org/10.14430/arctic795

Davidson-Hunt, I. J., and R. M. O'Flaherty. 2007. Researchers, indigenous peoples, and place-based learning communities. Society and Natural Resources 20(4):291-305. http://dx.doi. org/10.1080/08941920601161312

de Kerckhove, D. T., C. K. Minns, and B. J. Shuter. 2013. The length of environmental review in Canada under the Fisheries Act. Canadian Journal of Fisheries and Aquatic Sciences 70 (4):517-521. http://dx.doi.org/10.1139/cjfas-2012-0411

Dent, J. 2013. False frontiers: archaeology and the myth of the Canadian wilderness. Totem: the University of Western Ontario 
Journal of Anthropology 21(1): 7. [online] URL: http://ir.lib.uwo. ca/totem/vol21/iss $1 / 7$.

Deur, D., and N. J. Turner, editors. 2005. Keeping it living: traditions of plant use and cultivation on the northwest coast of North America. University of Washington Press, Seattle, Washington, USA.

Dietz, T., E. Ostrom, and P. C. Stern. 2003. The struggle to govern the commons. Science 302:1907-1912. http://dx.doi.org/10.1126/ science.1091015

Dowie, M. 2009. Conservation refugees: the hundred-year conflict between global conservation and native peoples. MIT Press, Boston, Massachusetts, USA.

Drew, J. A. 2005. Use of traditional ecological knowledge in marine conservation. Conservation Biology 19(4):1286-1293. http://dx.doi.org/10.1111/j.1523-1739.2005.00158.x

Favaro, B., J. D. Reynolds, and I. M. Côté. 2012. Canada's weakening aquatic protection. Science 337:154. http://dx.doi. org/10.1126/science. 1225523

Folke, C., S. Carpenter, T. Elmqvist, L. Gunderson, C. S. Holling, and B. Walker. 2002. Resilience and sustainable development: building adaptive capacity in a world of transformations. Ambio 31(5):437-440. http://dx.doi.org/10.1579/0044-7447-31.5.437

Gearheard, S., and J. Shirley. 2007. Challenges in communityresearch relationships: learning from natural science in Nunavut. Arctic 60(1):62-74. http://dx.doi.org/10.14430/arctic266

Government of Canada. 1982. Constitution Act, 1982 Section 35 (1). Government of Canada, Ottawa, Canada.

Gutiérrez, N. L., R. Hilborn, and O. Defeo. 2011. Leadership, social capital and incentives promote successful fisheries. Nature 470:386-389. http://dx.doi.org/10.1038/nature09689

Haggan, N., N. Turner, J. Carpenter, J. T. Jones, Q. Mackie, and C. Menzies. 2006. 12,000+ years of change: linking traditional and modern ecosystem science in the Pacific Northwest. Fisheries Centre, University of British Columbia, Vancouver, Canada. [online] URL: http://seannachie.ca/Website/Website-docs/12000yrs\% 20- $\% 20$ Haggan $\% 20$ et $\% 20$ al.pdf.

Heiltsuk Tribal Council. 2001. Guiding principles for scientific research in Heiltsuk Territory. Heiltsuk Tribal Council, Bella Bella, Canada.

Hoag, H. 2012. Canada's renowned freshwater research site to close: budget fall-out hits environmental research stations. Nature News, 21 May. http://dx.doi.org/10.1038/nature.2012.10683

Holling, C. S., and G. K. Meffe. 1996. Command and control and the pathology of natural resource management. Conservation Biology 10(2):328-337. http://dx.doi.org/10.1046/ j.1523-1739.1996.10020328.x

Houde, N. 2007. The six faces of traditional ecological knowledge: challenges and opportunities for Canadian co-management arrangements. Ecology and Society 12(2): 34. [online] URL: http:// www.ecologyandsociety.org/vol12/iss2/art34/.

Housty, W. G., A. Noson, G. W. Scoville, J. Boulanger, R. M. Jeo, C. T. Darimont, and C. E. Filardi. 2014. Grizzly bear monitoring by the Heiltsuk people as a crucible for First Nation conservation practice. Ecology and Society. 19(2): 70. http://dx.doi.org/10.5751/ ES-06668-190270

Huntington, H. P., S. Gearheard, A. R. Mahoney, and A. K. Salomon. 2011. Integrating traditional and scientific knowledge through collaborative natural science field research: identifying elements for success. Arctic 64(4):437-445. http://dx.doi. org/10.14430/arctic4143

Ingold, T., and T. Kurttila. 2000. Perceiving the environment in Finnish Lapland. Body and Society 6(3-4):183-196. http://dx.doi. org/10.1177/1357034X00006003010

Johannes, R. E. 2002. The renaissance of community-based marine resource management in Oceania. Annual Review of Ecology and Systematics 33:317-340. http://dx.doi.org/10.1146/ annurev.ecolsys.33.010802.150524

Johnson, M., and R. A. Ruttan. 1993. Traditional Dene environmental knowledge: a pilot project conducted in Ft. Good Hope and Colville Lake, N.W.T., 1989-1993. Dene Cultural Institute, Hay River, Canada.

Lemos, M. C., and A. Agrawal. 2006. Environmental governance. Annual Review of Environment and Resources 31:297-325. http:// dx.doi.org/10.1146/annurev.energy.31.042605.135621

Leys, A. J., and J. K. Vanclay. 2011. Social learning: a knowledge and capacity building approach for adaptive co-management of contested landscapes. Land Use Policy 28(3):574-584. http://dx. doi.org/10.1016/j.landusepol.2010.11.006

Loring, P. A. 2013. Alternative perspectives on the sustainability of Alaska's commercial fisheries. Conservation Biology 27 (1):55-63. http://dx.doi.org/10.1111/j.1523-1739.2012.01938.x

McGee, G., A. Cullen, and T. Gunton. 2010. A new model for sustainable development: a case study of The Great Bear Rainforest regional plan. Environment, Development and Sustainability 12(5):745-762. http://dx.doi.org/10.1007/s10668-009-9222-3

Moody, M. F. 2008. Eulachon past and present. Thesis. University of British Columbia, Vancouver, Canada.

Nadasdy, P. 2003. Reevaluating the co-management success story. Arctic 56(4):367-380. http://dx.doi.org/10.14430/arctic634 http:// dx.doi.org/10.14430/arctic634

Nicotera, N., N. Cutforth, E. Fretz, and S. S. Thompson. 2012. Dedication to community engagement: a higher education conundrum? Journal of Community Engagement and Scholarship 4(1). [online] URL: http://jces.ua.edu/dedication-to-communityengagement-a-higher-education-conundrum/.

Offshore Oil and Gas Research Group. 2004. A review of offshore oil and gas development in British Columbia. Report prepared for the Coastal First Nations. School of Resource and Environmental Management, Simon Fraser University, Burnaby, Canada. [online] URL: http://research.rem.sfu.ca/sustainableplanning/ CoastalFirstNationsOOGReport.pdf.

Ostrom, E. 2009. A general framework for analyzing sustainability of social-ecological systems. Science 325:419-422. http://dx.doi.org/10.1126/science.1172133 
Parrado-Rosselli, A. 2007. A collaborative research process studying fruit availability and seed dispersal within an indigenous community in the Middle Caquetá River region, Colombian Amazon. Ecology and Society 12(2): 39. [online] URL: http:// www.ecologyandsociety.org/vol12/iss2/art39/.

Parrotta, J. A., and R. L. Trosper, editors. 2012 Traditional forestrelated knowledge: sustaining communities, ecosystems and biocultural diversity. Springer, New York, New York, USA. http:// dx.doi.org/10.1007/978-94-007-2144-9

Pinkerton, E. 1999. Factors in overcoming barriers to implementing co-management in British Columbia salmon fisheries. Ecology and Society 3(2): 2. [online] URL: http://www. ecologyandsociety.org/vol3/iss 2/art2/

Pinkerton, E., and J. Silver. 2011. Cadastralizing or coordinating the clam commons: Can competing community and government visions of wild and farmed fisheries be reconciled? Marine Policy 35(1):63-72. http://dx.doi.org/10.1016/j.marpol.2010.08.002

Pretty, J. 2003. Social capital and the collective management of resources. Science 302:1912-1914. http://dx.doi.org/10.1126/ science. 1090847

Reynolds, J. D., I. M. Côté, and B. Favaro. 2012. Canada: a bleak day for the environment. Nature 487(7406):171. http://dx.doi. org/10.1038/487171b

Schnarch, B. 2004. Ownership, control, access, and possession (OCAP) or self-determination applied to research: a critical analysis of contemporary First Nations research and some options for First Nations communities. Journal of Aboriginal Health 1:80-95. [online] URL: http://www.naho.ca/jah/english/ jah01_01/journal_p80-95.pdf.

Smith, L. T. 1999. Decolonizing methodologies: research and indigenous peoples. Zed Books, London, UK.

Tobias, J. K., C. A. M. Richmond, and I. Luginaah. 2013. Community-based participatory research (CBPR) with indigenous communities: producing respectful and reciprocal research. Journal of Empirical Research on Human Research Ethics: An International Journal 8(2):129-140. http://dx.doi. org/10.1525/jer.2013.8.2.129

Tobias, T. N. 2000. Chief Kerry's moose: a guidebook to land use and occupancy mapping, research design and data collection. Union of BC Indian Chiefs and Ecotrust Canada, Vancouver, Canada. [online] URL: http://www.ubcic.bc.ca/files/PDF/Tobias whole. pdf.

Tobias, T. N. 2010. Living proof: the essential data-collection guide for Indigenous use-and-occupancy map surveys. Union of $\mathrm{BC}$ Indian Chiefs and Ecotrust Canada, Vancouver, Canada.

Todorovich, P., and D. Schned. 2012. Getting infrastructure going: expediting the environmental review process. Regional Plan Association, New York, New York, USA. [online] URL: http:// www.rpa.org/library/pdf/RPA-Getting-Infrastructure-Going.pdf.

Trosper, R. L. 2009. Resilience, reciprocity and ecological economics: Northwest Coast sustainability. Routledge, London, UK.
Turner, N. J., and F. Berkes. 2006. Coming to understanding: developing conservation through incremental learning in the Pacific Northwest. Human Ecology 34(4):495-513. http://dx.doi. org/10.1007/s10745-006-9042-0

Turner, N. J., and J. Carpenter. 1999. Collaborative research between communities and universities; a case study between the Heiltsuk and the University of Victoria School of Environmental Studies: "Looking After the Salmon Project" with James T. Jones. Final report to Forest Renewal BC. University of Victoria School of Environmental Studies, Victoria, Canada.

Turner, N. J., M. B. Ignace, and R. Ignace. 2000. Traditional ecological knowledge and wisdom of Aboriginal peoples in British Columbia. Ecological Applications 10(5):1275-1287. http://dx.doi.org/10.1890/1051-0761(2000)010[1275:TEKAWO]2.0. $\mathrm{CO} ; 2$

Walter, E., R. M. M'Gonigle, and C. McKay. 2000. Fishing around the law: the Pacific Salmon management system as a "structural infringement" of Aboriginal rights. McGill Law Journal 45(1):263-314. [online] URL: http://lawjournal.mcgill.ca/ userfiles/other/5944322-45. Walter.pdf.

Weiss, K., M. Hamann, and H. Marsh. 2013. Bridging knowledges: understanding and applying indigenous and western scientific knowledge for marine wildlife management. Society and Natural Resources 26(3):285-302. http://dx.doi.org/10.1080/089$\underline{41920.2012 .690065}$

White, E. A. F. (Xanius). 2006. Heiltsuk stone fish traps: products of my ancestor's labour. Thesis. Simon Fraser University, Burnaby, Canada.

Wyatt, S. 2008. First Nations, forest lands, and "aboriginal forestry" in Canada: from exclusion to comanagement and beyond. Canadian Journal of Forest Research 38(2):171-180. http://dx.doi.org/10.1139/X07-214 